\title{
Comunicação
}

[Communication]

\section{Expressão imunoistoquímica da proteína S-100 na discondroplasia da tíbia}

\author{
[S-100 protein immunostaining in tibial dyschondroplasia $]$
}

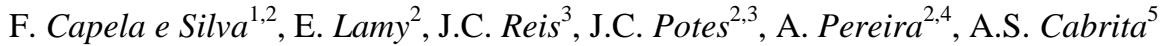 \\ ${ }^{1}$ Departamento de Biologia, Universidade de Évora, Portugal \\ ${ }^{2}$ Instituto de Ciências Agrárias e Ambientais Mediterrânicas (ICAAM), Universidade de Évora, Portugal \\ ${ }^{3}$ Departamento de Medicina Veterinária, Universidade de Évora, Portugal \\ ${ }^{4}$ Departamento de Zootecnia, Universidade de Évora, Portugal \\ ${ }^{5}$ Instituto de Patologia Experimental, Universidade de Coimbra, Portugal
}

A discondroplasia da tíbia é uma patologia das placas de crescimento epifisárias dos ossos longos das estirpes de rápido crescimento de espécies avícolas, caracterizada por anomalias na diferenciação dos condrócitos, traduzindo-se na acumulação de uma massa cartilagínea branca, opaca, não calcificada e avascular (Orth e Cook, 1994). Para além do aparecimento espontâneo, com forte base genética, vários fatores afetam a incidência e a gravidade das lesões discondroplásicas (Orth e Cook, 1994). Os trabalhos realizados têm caracterizado a cartilagem discondroplásica relativamente à expressão de vários genes e seus produtos (Farquharson e Jefferies, 2000; Praul et al., 2000; Leach e Monsonego-Ornan, 2007). Sua etiologia não está ainda devidamente esclarecida, sendo de supor uma origem multifatorial (Orth e Cook, 1994).

As proteínas S-100 constituem uma família de proteínas citoplasmáticas de baixo peso molecular, que se podem ligar ao $\mathrm{Ca}^{2+}$, ao $\mathrm{Zn}^{2+} \mathrm{e}$ ao $\mathrm{Cu}^{2+}$ e que estão envolvidas em muitos processos biológicos importantes (Donato, 2003). Inicialmente foram descritas como sendo específicas do sistema nervoso, tendo sido, no entanto, identificadas noutros tecidos, incluindo a cartilagem e o osso (Weiss e Dorfman, 1986; Dascalu et al., 1996; Balmain et al., 2003). O presente trabalho teve como objetivo principal avaliar a expressão imunoistoquímica da proteína S-100 na discondroplasia da tíbia.
Frangos de corte, da linhagem Cobb, foram criados em sistema padronizado, desde o dia do nascimento até aos 21 dias de idade (dieta e água foram disponibilizadas ad libitum), cumprindo as normas de bem-estar animal (FELASA, $<$ http://www.felasa.eu>). Foram estabelecidos dois grupos com 20 animais cada, sendo um grupo-controle e um grupo experimental. Para obtenção de animais com lesões discondroplásicas, incorporou-se à dieta o ditiocarbamato Tirame (CAS no 137-26-8, SIGMA, $\mathrm{n}^{\circ}$ T5638), na concentração de $35 \mathrm{mg} / \mathrm{kg}$. Ao fim de 21 dias, e após anestesia, os animais foram sacrificados por deslocamento cervical, seguido por remoção da tíbia esquerda e seccionamento longitudinal de sua epífise proximal. Os fragmentos obtidos foram imediatamente fixados em formaldeído neutro a $10 \%$, tamponado, durante 24 horas, após o que se procedeu à sua desmineralização em EDTA a $5 \%, \mathrm{pH} 7,4$, durante 7-10 dias.

Após a desmineralização, os fragmentos foram processados em um sistema automático, incluídos em parafina e cortados em micrótomo em secções com $5 \mu \mathrm{m}$ de espessura. As secções foram estendidas em lâminas de vidro de $75 \mathrm{x}$ $25 \mathrm{~mm}$, tratadas com polilisina. Para a imunoistoquímica, utilizou-se o método LAB-SA (UltraVision Detection System Kit, NeoMarkers, USA, ref. TP-015-HD), de acordo com as indicações do fabricante, com anticorpo primário comercial (NeoMarkers, ref. RB-044, diluição $1: 100$, e incubação overnight, a $4^{\circ} \mathrm{C}$ ). Como

Recebido em 28 de outubro de 2009

Aceito em 26 de fevereiro de 2010

E-mail: fcs@uevora.pt 
controle negativo, usaram-se secções sem o anticorpo primário. As preparações definitivas foram observadas em microscópio (Nikon Eclipse 600), com a ampliação de 100x, em secções correspondendo a 4-5 animais/grupo e uma secção/animal, sendo as imagens obtidas por meio de câmara digital Nikon DN100.

Foram observados condrócitos positivos na zona de hipertrofia, nas placas de crescimento normais e discondroplásicas (Fig. 1 e Tab. 1). Nestas últimas, foi evidente a expressão citoplasmática

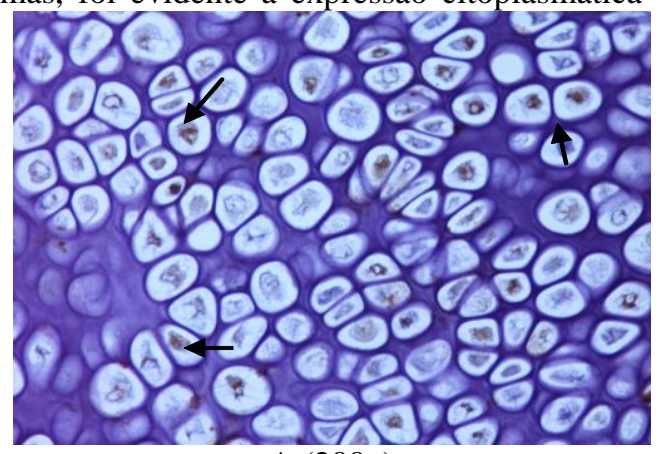

A $(200 x)$

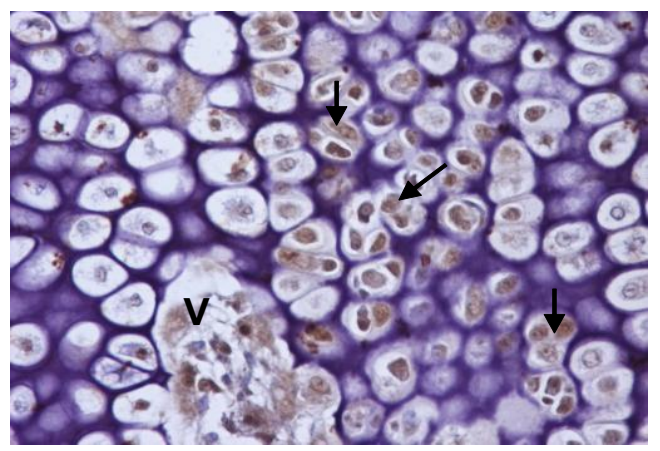

B (200x)

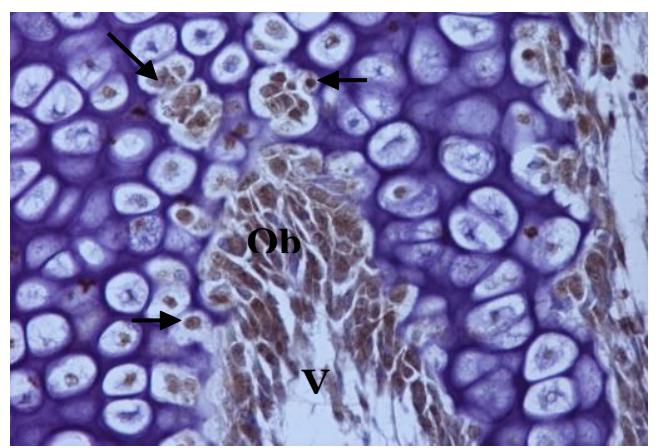

$\mathrm{C}(200 \mathrm{x})$ da proteína S-100 no interior das lesões, embora algumas células proliferativas tenham exibido expressão nuclear. Alguns condrócitos na fase final de hipertrofia, junto aos canais vasculares e aos locais de mineralização, mostraram, igualmente, imunomarcação citoplasmática intensa. Evidenciou-se também imunomarcação positiva de osteoblastos, osteoclastos, osteócitos e de inúmeras células da medula óssea. Não foi observada imunomarcação nas secções de controle negativo.

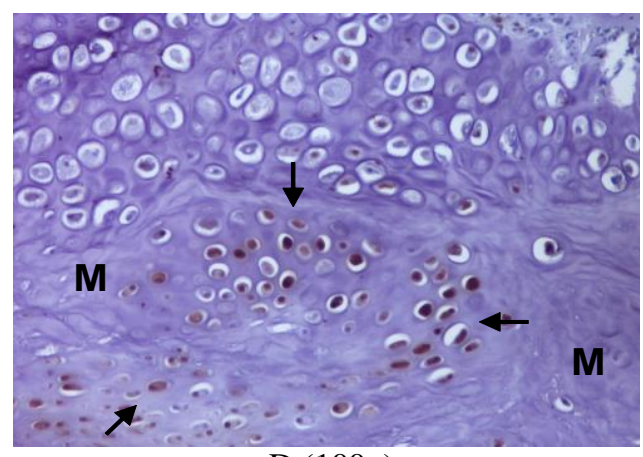

D $(100 x)$

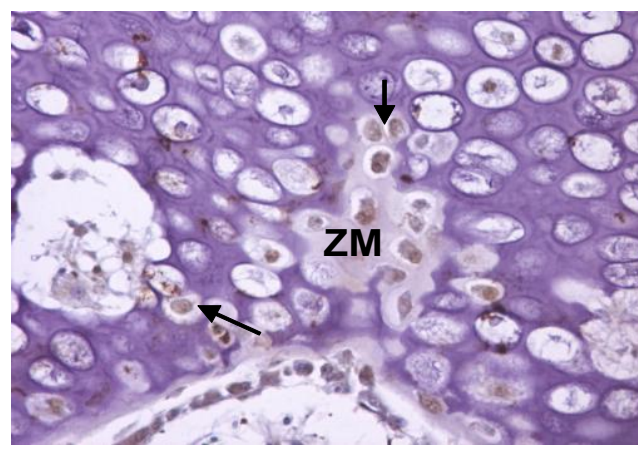

E (200x)

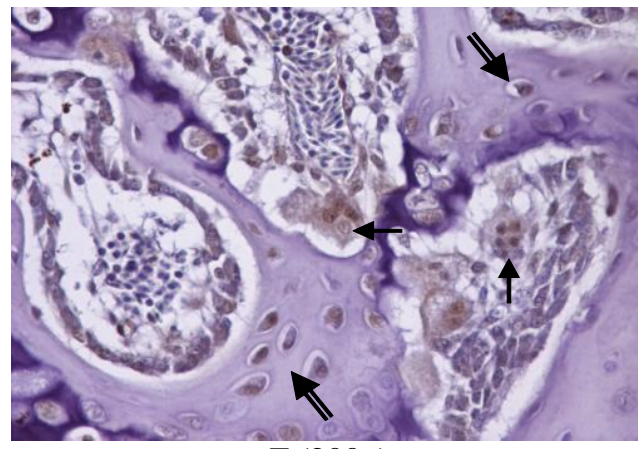

$\mathrm{F}(200 \mathrm{x})$

Figura 1. Imunoexpressão da S-100. Tíbia, frango de corte. Placas de crescimento normais (A, B, C): são visíveis condrócitos hipertróficos (setas) e osteoblastos $(\mathrm{Ob})$ positivos $(\mathrm{V}=$ canais vasculares). Placas de crescimento discondroplásicas (D, E, F): em D, são visíveis condrócitos hipertróficos positivos (setas) no interior de zona de lesão, com acumulação de matriz (M) e, em E, junto à zona de mineralização (ZM); em F, observam-se osteoclastos (setas simples) e osteócitos (dupla seta), positivos. Contracoloração com hematoxilina de Mayer. 
Expressão imunoistoquímica...

Tabela 1. Expressão imuno-histoquímica da proteína S-100 em tíbia de frango de corte

\begin{tabular}{lcc} 
Tipo celular & Normal & Discondroplasia \\
\hline Condrócitos de reserva & negativo & \pm \\
Condrócitos proliferativos & negativo & \pm \\
Condrócitos hipertróficos & \pm & + \\
Osteoblastos & + & + \\
Osteoclastos & +++ & +++ \\
Osteócitos & ++ & +++ \\
Medula óssea & + & + \\
\hline
\end{tabular}

Imunomarcação: ocasional, focal $= \pm$; fraca $=+$; moderada $=++$; intensa $=+++$.

Os resultados obtidos estão de acordo com os de outros autores, uma vez que foram observados condrócitos positivos fundamentalmente na zona de hipertrofia e junto aos canais vasculares, nas placas de crescimento normais (Weiss e Dorfman, 1986), e nas placas de crescimento discondroplásicas, embora algumas células proliferativas tenham exibido expressão nuclear. Nas placas de crescimento discondroplásicas, foram observados condrócitos hipertróficos positivos no interior das lesões, o que pode estar associado à reparação dos tecidos adjacentes (Leonardi et al., 2000), ou pode tratar-se de uma resposta à situação de inflamação crônica derivada do estresse bioquímico e mecânico provocado pela acumulação de matriz (Dascalu et al., 1996).

Os dados deste trabalho sugerem ainda que as proteínas da família S-100 podem estar envolvidas na proliferação, na hipertrofia e na apoptose dos condrócitos, como evidenciado por outros autores para outros tecidos (Donato, 2003), na estimulação da angiogênese da placa de crescimento (Ambartsumian et al., 2001) e na participação da homeostase do cálcio (Barger e Van Eldik, 1992). O conhecimento da participação das proteínas S-100 na mineralização da cartilagem (Weiss e Dorfman, 1986; Balmain et al., 2003) e do seu envolvimento na regulação da remodelação da matriz extracelular, influenciando a expressão das metaloproteinases da matriz (MMPs) e dos seus inibidores tecidulares (TIMPs) (Elenjord et al., 2008), torna interessante um estudo mais aprofundado sobre a eventual ligação dessas proteínas no desenvolvimento de lesões discondroplásicas.

A expressão da proteína S-100 nos osteoblastos, nos osteoclastos e nos osteócitos, bem como em inúmeras células da medula óssea, similar em ambos os tipos de placas de crescimento, provavelmente, estaria relacionada com a participação da S-100 na proliferação, na diferenciação - processos essenciais no normal decurso da ossificação endocondral - e na sobrevivência desses tipos celulares (Donato, 2003).

Palavras-chave: frango de corte, tíbia, discondroplasia, proteína S-100, imunoistoquímica

\begin{abstract}
It was compared, by immunohistochemistry, the expression of $S-100$ protein from normal and tibial dyschondroplasia (TD) growth plates. The results suggest that $S-100$ may be involved in growth plate homeostasis. The expression of S-100 in dyschondroplastic chondrocytes may be due to a low level of calcium in the lesion and/or compression of chondrocytes by the accumulated matrix. One further possibility is the association between $S-100$ and the regulation of matrix metalloproteinases (MMPs) and their endogenous inhibitors (TIMPs). Further studies will be necessary to provide insight into involvement of S-100 in tibial dyschondroplasia development and the precise nature of the pathology.
\end{abstract}

Keywords: broiler, tibia, dyschondroplasia, S-100 protein, immunohistochemistry 


\section{REFERÊNCIAS BIBLIOGRÁFICAS}

AMBARTSUMIAN, N.; KLINGELHOFER, J.; GRIGORIAN, $M$. et al. The metastasisassociated Mts1 (S100A4) protein could act as an angiogenic factor. Oncogene, v.20, p.46854695, 2001.

BALMAIN, N.; MOUTAHIR, F.; HEIZMANN, C.W. et al. Immunolocalization of S100A2 calcium-binding protein in cartilage and bone cells. Cell Mol. Biol. (Noisy-le-grand), v.49, p.485-486, 2003.

BARGER, S.W.; VAN ELDIK, L.J. S100 beta stimulates calcium fluxes in glial and neuronal cells. J. Biol. Chem., v.267, p.9689-9694, 1992.

DASCALU, A.; KORENSTEIN, R.; ORON, Y. et al. A hyperosmotic stimulus regulates intracellular $\mathrm{pH}$, calcium, and $\mathrm{S}-100$ protein levels in avian chondrocytes. Biochem. Biophys. Res. Commun., v.227, p.368-373, 1996.

DONATO, R. Intracelular and extracellular roles of S100 proteins. Microsc. Res. Tech., v.60, p.540-551, 2003.

ELENJORD, R.; LJONES, H.; SUNDKVIST, E. et al. Dysregulation of matrix metalloproteinases and their tissue inhibitors by S100A4. Connect. Tissue Res., v.49, p.185-188, 2008.
FARQUHARSON, C.; JEFFERIES, D. Chondrocytes and longitudinal bone growth: the development of tibial dyschondroplasia. Poultry Sci., v.79, p.994-1004, 2000.

LEACH, R.M. JR.; MONSONEGO-ORNAN, E. Tibial dyschondroplasia 40 years later. Poultry Sci., v.86, p.2053-2058, 2007.

LEONARDI, R.; VILLARI, L.; BERNASCONIC, G. et al. Cellular S-100 protein immunostaining in human dysfunctional temporomandibular joint discs. Arch Oral Biol., v.45, p.411-418, 2000.

ORTH, M.W.; COOK, M.E. Avian tibial dyschondroplasia, a morphological and biochemical review of the growth plate lesion and its causes. Vet. Pathol., v.31, p.403-414, 1994.

PRAUL, C.A.; FORD, B.C.; GAY, C.V. et al. Gene expression and tibial dyschondroplasia. Poultry Sci., v.79, p.1009-1013, 2000.

WEISS, A.P.; DORFMAN, H.D. S-100 protein in human cartilage lesions. J. Bone Joint Surg. Am., v.68, p.521-526, 1986. 